\title{
Editorial
}

\section{International Epilepsy Day}

Epilepsy is a common medical disorder that can have a psychological and emotional impact on people with the disorder and their families. It is an ancient disorder. The earliest detailed account of epilepsy can be found in Charaka Samhita dated 400 BC where epilepsy is being referred as Apasmara which means loss of consciousness and discusses both symptomatology and possible treatments for the same. Acharya Sushruta (600 BC), regarded as the father of surgery, also described various causes of apasmara. Its mention can also be found in British Museum, London as a part of a Babylonian text on medicine, Sakikku (All diseases), which was written over 3000 years ago, i.e. before 1000 BC. ${ }^{1}$

Later Hippocrates stated about Epilepsy, "This disease is in my opinion no more divine than any other; it has the same nature as other diseases, and the cause that gives rise to individual diseases. It is also curable, no less than other illnesses unless by long lapse of time it be so ingrained as to be more powerful than the remedies that are applied". Both Charaka and Hippocrates believed that epilepsy has natural cause and not a sacred or supernatural one. During 17 th and 18th centuries epilepsy was the topic of debate, which led to the development of modern neurology in the 19th century.

Epilepsy is under-recognized and often poorly funded with regard to clinical care and research. Therefore there is poor availability of treatment options for people with epilepsy around the world.
Current world population is approximately 7.28 billion. According to the WHO more than 50 million people worldwide have epilepsy and nearly $80 \%$ of the people with epilepsy are found in developing countries where annual new cases are between 40 per 100,000 to 70 per 100,000 people in the general population. In developing countries, this figure is often close to twice as high. The estimated proportion of the general population with active epilepsy at a given time is between 4 per 1000 and 10 per 1000 people. However, some studies in developing countries suggest that the proportion is between 6 per 1000 to 10 per $1000 .^{3}$

In the Global Burden of Disease Study 2010 survey, of almost 14,000 people from a range of global settings severe epilepsy was rated as having a disability adjusted life years (DALY) of 0.657 and total prevalent cases were $28,300,000{ }^{4}$ Disease burden for epilepsy has been evaluated in economic terms by the European Brain Council for the European countries, with data from $2004^{5,6}$ and 2010 , $^{7}$ based on epidemiological and health economic data which amounts to 161 and 212 million euros, respectively.

It is estimated that there are more than 10 million persons with epilepsy in India. Its prevalence is about $1 \%$ in our population. ${ }^{8}$ The prevalence is higher in the rural (1.9\%) compared to urban population $(0.6 \%)^{9,10}$ It is estimated in various studies that the overall prevalence of epilepsy in India is 5.59-10 per $1000 .^{8,10-12}$

Various epilepsy days celebrated across the world are:

\begin{tabular}{|c|c|c|c|}
\hline & Region/Country & Date & Organizers \\
\hline National Epilepsy Day & India & 17th November, started in 1991 & $\begin{array}{l}\text { Started with proposal of Doctors Eddie Bharucha \& } \\
\text { Piloo Bharucha of Indian Epilepsy Association }\end{array}$ \\
\hline $\begin{array}{l}\text { Latin American } \\
\text { Epilepsy Day }\end{array}$ & Latin America & 9th September, started in 2000 & $\begin{array}{l}\text { A global campaign against epilepsy of International } \\
\text { Bureau of Epilepsy (IBE) \& International League } \\
\text { Against Epilepsy (ILAE) }\end{array}$ \\
\hline National Epilepsy Day & South Africa & 21st June, started in 2003 & Started by Epilepsy South Africa organization \\
\hline $\begin{array}{l}\text { National Doodle Day } \\
\text { for Epilepsy }\end{array}$ & United Kingdom & $\begin{array}{l}\text { 1st Friday of February/March, } \\
\text { started in } 2004\end{array}$ & $\begin{array}{l}\text { Charity Epilepsy Action as an annual fund } \\
\text { raising event }\end{array}$ \\
\hline Purple Day & Canada & $\begin{array}{l}\text { 26th March, started in } 2008 \\
\text { Started in March } 2011 \text { in India }\end{array}$ & Started by Cassidy Megan of Nova Scotia, Canada \\
\hline European Epilepsy Day & Europe & $\begin{array}{l}\text { Second Monday February, } \\
\text { started in } 2011\end{array}$ & $\begin{array}{l}\text { An initiative of the Joint Task Force of IBE and } \\
\text { ILAE against epilepsy }\end{array}$ \\
\hline
\end{tabular}


The Indian Epilepsy Association (IEA) was registered in 1970. In the late 1960s it was decided by some members of Neurological Society of India (NSI) to form a separate body to address issues related to epilepsy. Dr Anil D Desai, Dr Eddie P Bharucha and Dr Noshir H Wadia went about to form a new society named Indian Epilepsy Association, without disturbing the constitution of NSI. Indian Epilepsy Association was registered on 21st of March 1970 in Bombay. The members of first Governing council were Dr Baldev Singh, Dr B Ramamurthi, Dr TK Ghosh, Dr EP Bharucha, Dr AD Desai, Dr NH Wadia, Dr KV Mathai, Dr KS Mani and Mrs Roshan H Dastur. The first meeting was held on 27th of January 1971 where Dr Baldev Singh was appointed as Chairman, Dr Eddie P Bharucha as Secretary General and Dr (Miss) FN Kohiyar as Treasurer. Initially IEA was affiliated to both IBE and ILAE. However, both IBE and ILAE did not agree for one association to be affiliated to two bodies. Hence an independent body, Indian Epilepsy Society (IES) was formed in 1997 which was affiliated to ILAE. Indian Epilepsy Association continued its affiliation to IBE.

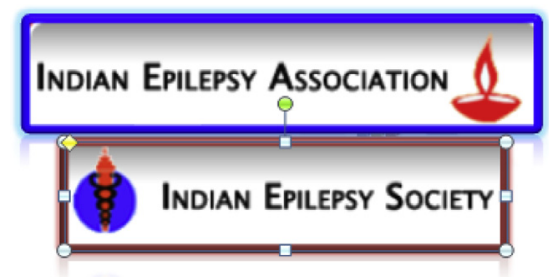

In the General Body Meeting of IEA held at Indore on 16 December 1990, Dr Eddie Bharucha and Dr Piloo Bharucha proposed a nationwide program on one particular day to create awareness. Their proposal was supported by other members and it was finally decided to celebrate 17 November of every year as National Epilepsy Day (NED). From 2015 onwards, the NED will be replaced by International Epilepsy Day.

National Epilepsy Day 2014 was celebrated across the country in Vizag, Kochi, Madhya Pradesh, Jaipur, Uttar Pradesh and Tirupati.
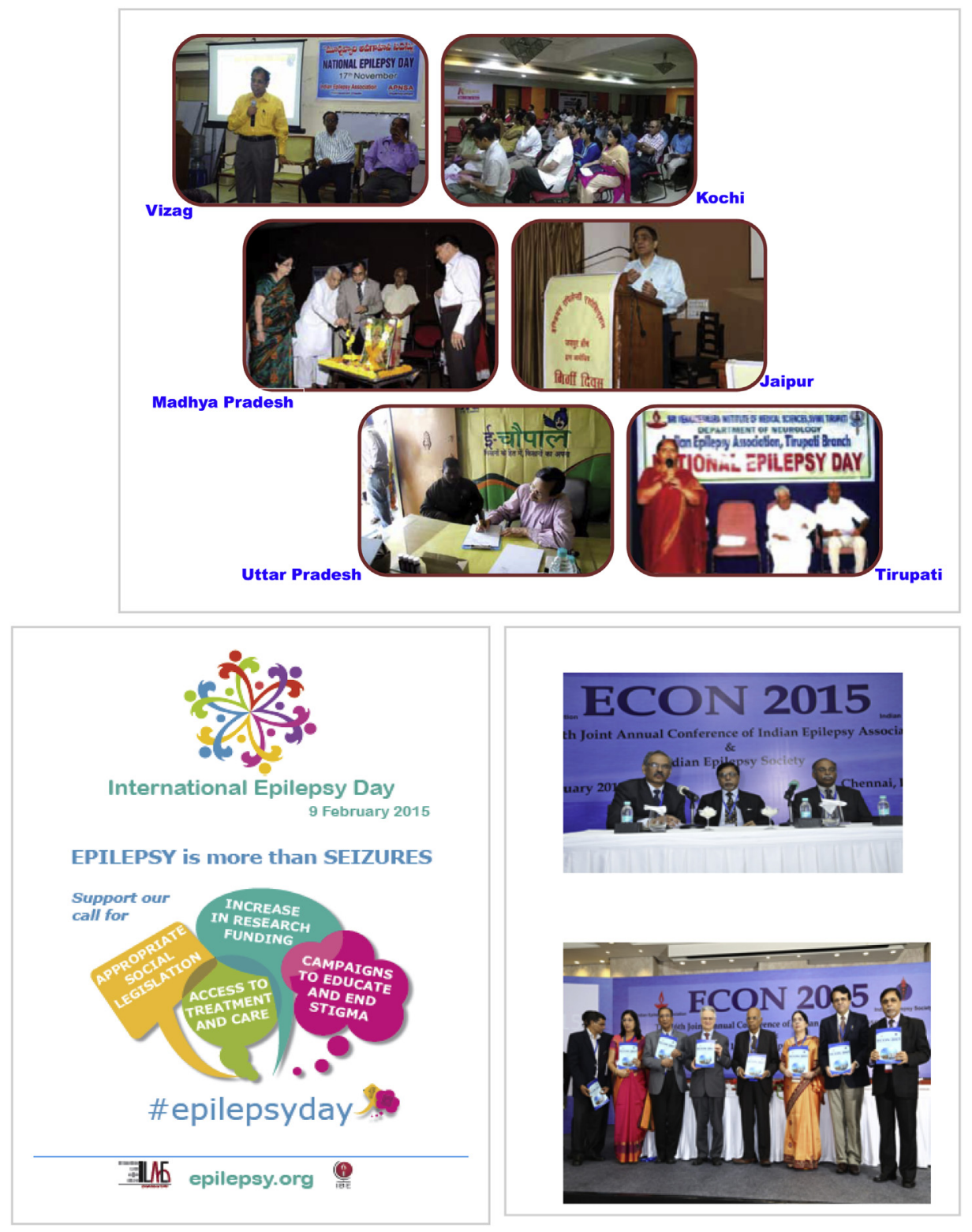
An executive meeting by IBE \& ILAE was held on June 27, 2014, in Stockholm, wherein after voting, it was decided that the second Monday of February should be celebrated as International Epilepsy Day, which has also been the European Epilepsy Day (EED) since 2011. The date is close to the celebration of Valentine's Day. It is a commonly held belief that St. Valentine had epilepsy. International Epilepsy Day, a joint initiative created by IBE and ILAE. This year it was celebrated across 138 countries on 9th of February and will be celebrated globally on 2nd Monday of February to promote awareness of Epilepsy and emphasize need for advancement in health care and research. International Bureau of Epilepsy and International League Against Epilepsy invited participants from all over the world to design perfect logo for the International Epilepsy Day campaign.

The winner of the competition for International Epilepsy Day logo was Mr Masgustian, a student of Gadjah Maha University, Indonesia in which Human Silhouettes represent togetherness and common goal to care for and understand people with epilepsy. Different colors represent the fact that people of all ages are affected by Epilepsy and we must accept it and embrace the diversity. This is a day for everyone regardless of your location, race, ethnicity and cultural background and also allows a common platform for people with epilepsy across the globe to share their experiences, struggles and stories with the world.

The aims of International Epilepsy Day are:

* To raise awareness of the disease at international and government level as well as in the general public.

* To strengthen the epilepsy movement by uniting epilepsy associations.

* To raise visibility on epilepsy and encourage discussion about epilepsy.

* To provide epilepsy associations with a significant fund raising opportunity.

Seventy percent of newly diagnosed children and adults with epilepsy can be successfully treated with anti-epileptic drugs (AEDs). Drugs can be withdrawn in about $70 \%$ of children and $60 \%$ of adults without relapses after $2-5$ years of successful treatment. Approximately three-fourths of people with epilepsy in developing countries may not receive the treatment they need. Moreover in many low- and middleincome countries it's difficult to access treatment due to low availability and unaffordability of AEDs. ${ }^{3}$

Epilepsy is a cost intensive disorder. Developing countries carry $90 \%$ of the financial burden of epilepsy as $85 \%$ of world's 40 million people with epilepsy (PWE) live in developing countries. ${ }^{13-15}$ In a landmark multicentric study to study the cost of epilepsy in India, the total annual cost per people amounted to INR 13,755 (USD 344). The total economic burden of epilepsy in India was found to be INR 68.75 billion (1.72 billion USD) which constituted 0.5\% GNP of India. ${ }^{16}$

There are dramatic global disparities in the care of epilepsy peoples between high- and low-income countries and between rural and urban settings. If treated properly, up to $75 \%$ of PWE can lead a normal seizure-free life and $20-30 \%$ of PWE have spontaneous remission of seizures without treatment. ${ }^{17}$ The magnitude of epilepsy treatment gap in India ranges from $22 \%$ among urban, middle-income people to $90 \%$ in villages ${ }^{18}$ which is influenced by lack of access to/knowledge of antiepileptic drugs, poverty, cultural beliefs, stigma, poor health delivery infrastructure, shortage of trained professionals, inequitable distributions of available resources in rural areas and high cost of treatment. ${ }^{19-21}$

Efforts should be made to reduce the treatment gap in epilepsy. A substantial proportion of the current large treatment gap in epilepsy in developing countries could be minimized by educating the primary care physicians about the diagnosis of epileptic seizures, cost-effective AED treatment, availability of specialist health professionals in low- and middle-income countries and need-based referral for specialized care. ${ }^{22}$

Epilepsy due to perinatal brain injury remains an important problem in developing countries and contributes significantly to the burden of epilepsy in developing world. Predominant causes are perinatal asphyxia, neonatal hypoglycemia, sepsis-meningitis, late hemorrhagic disease of the newborn and perinatal ischemic arterial stroke, all of which are preventable. ${ }^{23}$

For many years, IBE, ILAE and WHO have been working on a series of initiatives and campaigns to increase public awareness about epilepsy and to improve treatment options for people with epilepsy around the world. In 1997, WHO, ILAE and IBE launched the Global Campaign against Epilepsy- "Out of the Shadows" and in 2008 WHO launched its mental health gap action program. This year's central theme for World Brain Day campaign, which will be celebrated on 22nd July, is Epilepsy. International Epilepsy Day was celebrated one day prior at ECON 2015 (16th Joint Annual Conference of Indian Epilepsy Association \& Indian Epilepsy Society), Chennai on 8th of February as the last day of conference coincided with IED.

International Epilepsy Day will definitely improve public awareness and raise visibility of epilepsy globally which will ultimately lead to improved access to AEDs, provision of costeffective treatment, improved funding for research activity in epilepsy and development of appropriate legislation to protect the rights of all people with epilepsy.

\section{R E F E R E N C E S}

1. Kinnier Wilson JV, Reynolds EH. Translation and analysis of a cuneiform text forming part of a Babylonian treatise on epilepsy. Med Hist. 1990;34:185-198.

2. Hippocrate. De la maladie sacree, livre 6. In: Oeuvres Completes d' Hippocrate. Littre E, ed., 1849B;364.

3. Fact sheet. Epilepsy: World Health Organization. 2012.

4. Whiteford HA, Ferrari AJ, Degenhardt L, Feigin V, Vos T. The global burden of mental, neurological and substance use disorders: an analysis from the Global Burden of Disease Study 2010. Forloni G, ed. PLoS ONE. 2015;10:e0116820.

5. Andlin-Sobocki P, Jonsson B, Wittchen HU, Olesen J. Cost of disorders of the brain in Europe. Eur J Neurol. 2005;12:1-27.

6. Stovner LJ, Gjerstad L, Gilhus NE, Storstein A, Zwarta JA. Cost of disorders of the brain in Norway. Acta Neurol Scand Suppl. 2010;190:1-5.

7. Gustavsson A, Svensson M, Jaconbi F, et al. Cost of disorders of the brain in Europe 2010. Eur Neuropsychopharmacol. 2011;21:718-779.

8. Sridharan R, Murthy BN. Prevalence and pattern of epilepsy in India. Epilepsia. 1999;40:631-636. 
9. Pahl K, de Boer HM. Epilepsy and rights. In: Atlas: Epilepsy Care in the World. Geneva: WHO; 2005:72-73.

10. Gourie-Devi M, Gururaj G, Satishchandra P, Subbakrishna DK. Prevalence of neurological disorders in Bangalore, India: a community-based study with a comparison between urban and rural areas. Neuroepidemiology. 2004;23:261-268.

11. Sridharan R. Epidemiology of epilepsy. Curr Sci. 2002;82:664-670.

12. Goel D, Agarwal A, Dhanai JS, et al. Comprehensive rural epilepsy surveillance programme in Uttarakhand state of India. Neurol India. 2009;57:355-356.

13. World Bank Report. New York: Oxford University Press; 1993:216-292.

14. Pedley T, Kale R. Epilepsy information for the developing world. Epilepsia Dig. 1996;1:1.

15. Anonymous. Economic Cost and Evaluation: Campaign Information 6. Epilepsy Out of the Shadows. Bielefeld: International League Against Epilepsy; 1997.

16. Thomas SV, Sarma PS, Alexander M, et al. Economic burden of epilepsy in India. Epilepsia. 2001;42:1052-1060.

17. Kwan P, Sander JW. The natural history of epilepsy: an epidemiological view. J Neurol Neurosurg Psychiatry. 2004;75:1376-1381.

18. Meyer AC, Dua T, Ma J, Saxena S, Birbeck G. Global disparities in the epilepsy treatment gap: a systematic review. Bull World Health Organ. 2010;88:260-266.

19. Meinardi H, Scott RA, Reis R, Sander JW, ILAE Commission on the Developing World. The treatment gap in epilepsy: the current situation and ways forward. Epilepsia. 2001;42:136-149.

20. Scott RA, Lhatoo SD, Sander JW. The treatment of epilepsy in developing countries: where do we go from here? Bull World Health Organ. 2001;79:344-351.

21. Radhakrishnan $\mathrm{K}$. Challenges in the management of epilepsy in resource-poor countries. Nat Rev Neurol. 2009;5:323-330.

22. Iyer RS, Rekha M, Kumar TS, Sarma PS, Radhakrishnan K. Primary care doctors' management behavior with respect to epilepsy in Kerala, southern India. Epilepsy Behav. 2011:137-142.

23. Udani V, et al. Epilepsies due to perinatal brain injuries: focus on prevention. Neurol Asia. 2011;16:17-19.

Dr. Man Mohan Mehndiratta, Prof. \& HOD

Department of Neurology, Janakpuri Superspeciality Hospital, New Delhi, India

Dr. Swati Wadhai Senior Resident, Janakpuri Superspeciality Hospital, New Delhi, India

http://dx.doi.org/10.1016/S2213-6320(15)00036-6 